\title{
Training Teachers to Use Globisens Labdiscs for Citizen Science Projects in School
}

\author{
Külli Kori \\ Tallinn University \\ Kai Pata \\ Tallinn University
}

Four schools in Estonia received Globisens Labdiscs with sensor technology enabling to collect scientific data about different aspects of environment with the aim to use these in Citizen Science (CS) related activities. The teachers were trained for this and they thought that CS approach has a great potential for using in school. However, the challenge is that at the beginning it is difficult for teachers and students to use the new technology. Adopting the CS paradigm may take time and participating more in real-life CS project could help guiding teacher to implement the CS approach in their teaching.

Keywords: citizen science, inquiry-based learning, STEM education, technology-enhanced learning

\section{INTRODUCTION}

\section{Citizen Science}

Citizen science (CS) projects engage regular people into carrying out scientific investigation together with professional scientists (Silvertown, 2009). In media, the term "citizen science" is used in a variety of practices, like citizens donating the processing power of their computers to perform scientific calculations, amateur naturalists collecting observational data outdoors about birds, city residents mapping air pollution, people classifying online images of galaxies from home, patients sharing observations, symptoms, and experiences about their health, and biohackers attempting to produce insulin in a community laboratory (Strasser et la., 2019). The term "citizen science" comes from Alan Irwin" book "Citizen Science: A Study of People, Expertise, and Sustainable Development" (Irwin, 1995). The initial goal of CS was to bring public and science together and involve citizens more in discussions and decision-making around environmental issues (Irwin, 1995). However, Richard Bonney (1996) started using the term a little differently. He defined CS as scientific projects which involve citizens as amateurs who collect large amount of observational data (e.g. bird watching) for scientists and acquire new skills in return. This definition has been criticised because several CS projects use citizens are only as data collectors and they cannot initiate their own investigation (Sharples, et al., 2017).

Different classifications of CS projects can be found from the literature. For example, CS projects can be divided into three categories: 1) contributory projects are designed by scientists and citizens help to collect data, 2) collaborative projects also involve citizens in refining the project design, analysing the data and disseminating findings, 3) co-created projects are designed together with scientists and citizens 
and citizens are involved in all the steps of the scientific process (Bonney, et al., 2009). Haklay (2013) also considered the levels of participation in the projects and divided CS projects into four hierarchical levels: 1) "crowdsourcing" involves citizens as sensors (e.g., volunteered computing), 2) "distributed intelligence" involves citizens as basic interpreters (e.g., volunteered thinking), 3) "participatory science" involves citizens in problem definition and data collection, 4) "extreme citizen science" is collaborative and involves citizens in problem definition, data collection and analysis. Another way to classify CS projects is based the goals of the projects and environments in which they are carried out. Based on that CS project can be divided into five categories: 1) action - reaching local civic agendas through science, 2) conservation - natural resource management, 3) investigation - data collection in a natural environment, 4) virtual - online scientific research projects, 5) education - science education in formal and informal settings (Wiggins \& Crowston, 2011).

Lately, CS has become more and more popular all over the world. Even European Commission's Open Science agenda (2018) emphasizes the importance of engaging citizens into active policy making by using scientific methods. The agenda says that European Union will not remain competitive without open science and open innovation. Open science increases collaboration, makes academic research more transparent, accessible and efficient (Friesike \& Schildhauer, 2015). In addition, participating in CS projects is beneficial for the citizens. They could develop their knowledge, increase the awareness of the diversity of scientific research, acquire new skills and contribute to social well-being by influencing the questions that are being addressed and by giving people a voice in local environmental decision making (Bonney, et al., 2016). Therefore, to grow active citizens who make decisions based on scientific data, already children from schools should be involved in CS projects.

\section{Citizen Science in Schools}

In school CS can be combined with inquiry-based learning (Sharples, et al., 2017). Inquiry-based learning is widely used in STEM education in Estonian schools as its importance is emphasized in the national curriculum (National Curriculum for Basic School, 2014) and students' inquiry skills are evaluated in the national test (Pedaste, et al., 2017). So, inquiry-based learning is a paradigm that Estonian teachers have probably already adopted. Still, usually the inquiry-based tasks that students work on in school only stay in the classroom and do not go close to the scope of CS where the inquiry is done openly and in collaboration with the scientists and society. CS is a new paradigm for the teachers and they need training to move from inquiry-based learning paradigm to more advanced CS paradigm. To adopt the new paradigm, teachers need inquiry skills, CS related technical skills and they need to value CS related teaching outcomes.

Various examples of CS projects involving school children can be found from the literature. For example, students have been involved in measuring air quality (Fjukstad, et al., 2018), analysing weather data (Kermish-Allen, et al., 2018), collecting data about marine litter (Eastman, et al., 2014) and monitoring different species like horseshoe crabs (Hiller \& Kitsantas, 2014) or frogs (Flagg, 2016). However, mostly in these projects students are only involved in the data collection and analysis phase. To involve the students more, researchers have merged CS and inquiry-based learning into one term - citizen inquiry (Sharples, et al., 2017). Citizen inquiry in school means that students have a question or topic of interest and they start an investigation around it. They also ask other people and scientists to join the investigation. They collect data that is shared and available for everyone, discuss the topics online and try to reach consensus about the findings.

Participating in CS projects has a great potential to develop students' knowledge, skills and attitude. For example, it has been found that participating in a CS project on the topic of weather developed students' knowledge about weather and climate (Kermish-Allen, et al., 2018) and participating in Red Sea coral reef monitoring program increased the participants' knowledge of coral reef biology and ecology (Branchini, et al., 2015). Also, positive effect of CS project has been found on participants' skills that are needed in the project (Newman, et al., 2010) and critical thinking skills (Caruso, et al., 2016). Participating in CS projects has found to increase participants' awareness of human behavioural impacts 
on the environment (Branchini, et al., 2015) and attitude toward the resources that they monitored in the CS project (Chase \& Levine, 2018).

As CS in new and innovative paradigm for Estonian schools, teacher need training on how to implement this approach, but the problem is that the teachers may not adapt it right away. Therefore, it needs investigation how to improve teacher training so that teachers will adopt CS paradigm more effectively. There are three phases of adapting an innovation that should be passed: 1) initiation (teachers learn about the existence of the innovation and consider its suitability), 2) adoption (teachers decide to adopt the innovation), and 3) implementation (teachers try to use the innovation, modify it and use it until it becomes a routine) (Damanpour \& Schneider, 2006). Also, the innovative approach could be adapted either on classroom level, teacher level or systematically on institutional level (Neyland, 2011). There are several attributes that have effect on adopting the new innovation like CS approach in school. According to the diffusion of innovation theory, it should have relative advantage compared to the approaches teachers used before, it should be compatible with the existing values, experiences and needs of the teachers, it should not be too difficult to understand and use, the teachers should have opportunities to try and experiment with the new innovation, and the results of using the innovative approach should be visible to others (Rogers, 1995). So, these are the aspects that teacher training could focus on.

CS projects that focus on environmental issues usually need specific sensor technology for data collection and different sensors are available in the market for schools. The current study focuses on four schools in Estonia that obtained Globisens Labdiscs (https://www.globisens.net/). These are compact, wireless devices with built-in sensors and external sensors that can be used in science classes. Four different models are available: 1) Labdisc Enviro for environment relates measures, 2) Labdisc BioChem for biochemistry related measures, 3) Labdisc Physio for physics related measures, and 4) Labdisc Gensci for core science concepts related measures. In addition, the devices can be connected to a computer or tablet where data can be analysed and visualised through Globilab software. The Globisens devices can be used in school for a variety of hands-on activities and inquiry-based learning, but the four schools have raised their goal to create a CS competence centre that leads CS practices to reach Estonian schools.

In the current study teachers from the four Estonian schools were trained to used Globisens Labdiscs for CS projects and teachers' experiences and perceptions were investigated. The aim of the study was to improve teacher training so that teacher will adopt the new CS paradigm more effectively. The following research questions were formulated for this study: 1) How teachers adopt the CS related technical skills and value CS related teaching outcomes during the trainings? 2) How previously adopted inquiry-based learning paradigm affects teaches to adopt the CS paradigm? 3) How teachers implement CS paradigm while creating teaching scenarios?

\section{METHODOLOGY}

\section{Teacher Training}

Four Estonian schools obtained Globisens Labdiscs (https://www.globisens.net/) and they were asked to send up to 10 teachers to participate at four teacher training events (the teachers did not have to be the same every time). Three of the training events took place in spring (once a month) 2019 and one training event was carried out after the summer break. The training events focused on the following topics:

- The first training event was in inquiry-based learning paradigm and focused on developing teachers' technical skills that are needed for CS. The event lasted half a day and the teachers learned what are the Globisens Labdiscs and Globilab software and how to use them. The teachers practiced this by solving few inquiry-based tasks.

- The second training event also lasted half a day and focused on one example of a CS project. So, the CS paradigm was introduced to the teachers for the first time. The teachers had to complete a task about urban heat island, measure temperatures of different surfaces outside, share the data with others and discuss about the collected data. Web-based environment Anecdata (https://www.anecdata.org/) was used for sharing the collected data and Tricider 
(https://www.tricider.com/) was used for discussing how to deal with the problem of urban heat islands.

- The third training event lasted a full day and focused on one Globisens device - Labdisc Enviro. The teachers had to complete tasks using each of the sensors that the Labdics Enviro has (ambient temperature, barometer, colorimeter, dissolved oxygen, external temperature, GPS, infrared temperature, $\mathrm{pH}$, relative humidity, sound level, turbidity, UV). Most of the tasks were in inquiry-based learning paradigm, but one was an example of a CS project about - which light sources to use for growing plants. In additions, teachers in groups developed some teaching scenario ideas that use Labdisc Enviro.

- The forth training day lasted a full day and focused on Labdisc Physio. The teachers completed tasks using the following sensors: accelerometer, air pressure, ambient temperature, current, distance (motion), external temperature, light, microphone, voltage. One of the tasks was an example of a CS project where teachers used light sensor to measure light luminous intensity in different rooms in the school building to see if the lighting is according to the health rules or not. The data was shared in Google sheet and is was discussed orally what should be changed in the enlightenment of the classrooms and other rooms in the school building.

The inquiry-based tasks and CS related tasks that the teachers completed during the trainings were built based on the inquiry-cycle (Pedaste, et al., 2015). This means that teachers had to formulate problems, hypothesis or research questions, plan and carry out experiments, share the data, make conclusions and discuss how to solve the problem.

\section{Participants}

The participants were teachers from four Estonian schools and they were teaching a variety of subjects. Some were science teachers, some language teachers, some physical education teachers, some elementary school teachers etc. The aim was to include teachers who teach different subjects for 4th to 9th grade students for interdisciplinary approach.

During each training event the teachers had to fill in a questionnaire. 30 teachers filled in the questionnaire at the first training event, 13 teachers at the second training event, 21 teachers at the third training event and 20 teachers at the fourth training events. There were more participants, but not all of them filled in the questionnaires which data were analysed in the current study.

\section{Data Collection and Analysis}

During each training event the participants answered a questionnaire that focused on teachers' perception about their technical skills of using Globisens Labdiscs and Globilab software, previous experiences of using inquiry-based learning and sensors with students, and if the teachers were able to complete the tasks that were given to them during the training. Questions about the task were based on the phases of inquiry cycle (Pedaste, et al., 2015). In addition, at the second, third and fourth training event the teachers answered a modified Citizen Science Outcome Expectations Scale (modified from (Hiller, 2012); the items were evaluated on 5-point scale. Most of the items in the modified Citizen Science Outcome Exercitations Scale fit with both inquiry-based learning paradigm and CS paradigm, but some items are more specific to one (e.g., developing inquiry skills fits more with inquiry-based learning paradigm and helping scientists with their work fits more with CS paradigm). Therefore, the scale enables to compare if the teacher valued higher the CS or inquiry-based learning outcomes. At the second training event the Citizen Science Outcome Expectations Scale focused on the task of urban heat islands, at the third training event the scale focused on the task of growing plants, and at the fourth training event the scale focused on the task of enlightenment in school. In this study, the answers of these three tasks were put together and the Cronbach value showed adequate reliability (0.729).

In addition to the questionnaires, at the second training event the teachers discussed in groups and wrote down how they would change the completed task so that they could use it in school with their 
students. At the third and fourth training event the teachers from each school wrote down teaching scenario ideas in order to investigate if they will implement CS paradigm in the scenarios or not. In addition, the researchers, who were training the teachers, wrote down their reflections about each training event.

In this paper, the answers to the questionnaires were analysed by descriptive statistics. Qualitative content analysis was used to analyse what teachers wrote down in groups and what researchers expressed in their reflections.

\section{RESULTS}

\section{CS Related Technical Skills and Evaluation of Teaching Outcomes}

At the first training day only $12.5 \%$ of the teachers had experience of using sensors in their classes, but none of the teachers had used Globisens sensors before. The number of teachers who had used sensors in their classes increased every time and by the fourth training day 35\% of the teachers had used sensors in their classes. Several of the teachers also shared their experiences of using Globisens Labdiscs with their students.

After each CS related task teachers evaluated if they were able to use the Globisens Labdiscs and Globisens software. The results show that the teachers had difficulties with using the new technology, but their perceptions about their technical skills improved during the trainings. The number of teachers who thought that they were able to use Globisens Labdiscs at the first training event was $33.3 \%$, but the number grow up to $75 \%$ by the fourth training event. The evaluation of the ability to use GlobiLab software also slightly increased - from $33.3 \%$ at the first training event to $42.9 \%$ by the third training event (Globilab software was not used at the fourth training day for CS related task). Another difficulty for the teachers was how to gather the data that different people collected into one dataset. For this Anecdata and Google Drive were used at the training events. At the first training day $50 \%$ of the teachers were able to gather the data, but the number increased by the fourth training day up to $85 \%$. However, the researchers' reflections indicated that the data gathering phase was not very smooth for the teachers as they were not used to working with the platforms like Anecdata or Google Drive. The teachers firstly wrote down the data on a paper and then inserted it to the electronic form which was not very comfortable.

After each CS related task, the teachers evaluated on 5-point scale the value of different CS related teaching outcomes on the modified Citizen Science Outcome Expectations Scale. All of the outcomes were quite highly valued (see Figure 1). 


\section{FIGURE 1 \\ TEACHER EVALUATIONS OF CS RELATED TEACHING OUTCOMES ON THE MODIFIED CITIZEN SCIENCE OUTCOME EXPECTATIONS SCALE}

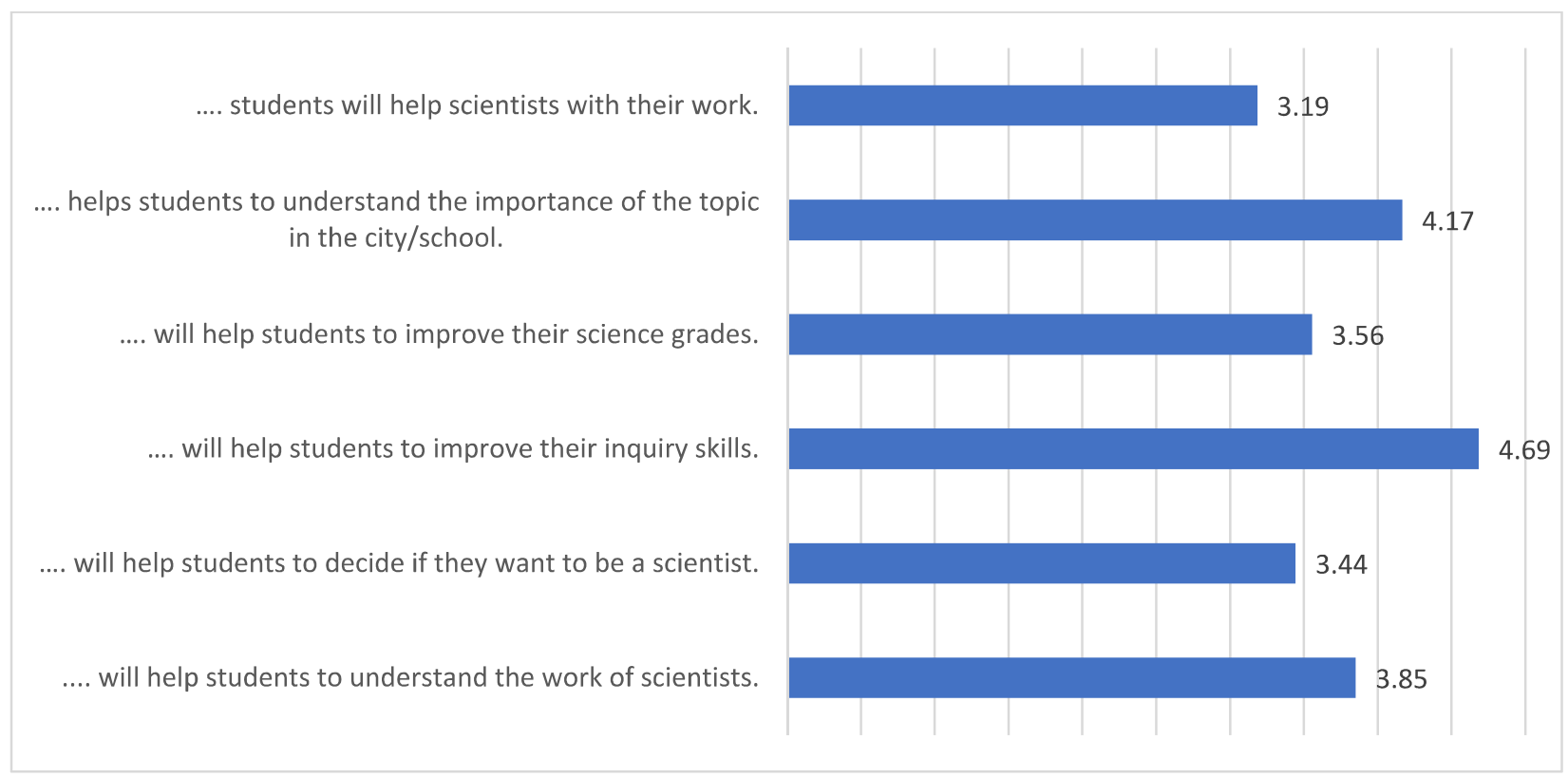

The highest valued outcome for the teachers was that the CS related task will improve students' inquiry skills $(\mathrm{M}=4.69, \mathrm{SD}=0.47)$ which clearly shows inquiry-based learning paradigm. The lowest valued outcome for the teachers was that with the CS related task students will help scientists with their work $(\mathrm{M}=3.19, \mathrm{SD}=1.07)$ which is more in the CS paradigm. The other outcomes in between those two can be related to both of the paradigms (e.g., both paradigms follow the steps of scientific research, and therefore, could help students to understand the work of scientists and to decide if they want to be a scientist). So, the results indicate all the outcomes were quite highly valued, but that the teachers valued the highest the outcomes of inquiry-based learning paradigm.

\section{Teachers' Experiences with Inquiry-Based Learning}

Most of the teachers who participated at the trainings had adopted the inquiry-based learning paradigm. At the first training event $66.7 \%$ of the teachers answered that they have used inquiry-based learning approach in their classes. This number increased up to $87 \%$ on the third training event. Still, some new teachers participated at the fourth training event and the percentage of teachers with previous experiences of using inquiry-based learning decreased to $70 \%$. After each CS task teachers also evaluated if they were able to complete the inquiry related steps of the tasks. In general, teachers evaluated their abilities quite highly and significant development was not found. Over $80 \%$ of the teachers reported every time that they were able to formulate the problem and hypothesis, plan the experiment, interpret data and make conclusions based on the collected data.

The inquiry-based learning paradigm definitely had effect on adopting CS paradigm as the teaches had inquiry-based skills that are also need in CS paradigm. Still, the researchers' reflections showed that inquiry-based learning paradigm was more familiar for the teacher and it was easier for them to stay at the familiar paradigm. The teachers had a potential of moving towards the CS paradigm, but according to the researchers' reflections, only few of them showed that they are thinking in the new paradigm.

\section{Teaching Scenarios That Use Globisens Labdiscs}

During the third and fourth training event teachers in groups developed new teaching scenario ideas that use Globisens Labdiscs. During the third training event 7 teaching scenario ideas were developed: 2 
of the scenarios used temperature sensor, 2 used colorimeter, 1 used infrared temperature sensor, 1 used turbidity sensor, and 1 used $\mathrm{pH}$ sensor. The ideas were mostly in inquiry-based learning paradigm. Still, one idea related in CS paradigm was created by the teachers. It was a scenario including the school community into measuring room temperatures in different parts of the school building and analysing what should be changed in the system of heating or cooling down the building.

During the fourth training event teachers in groups developed 17 teaching scenarios that used Globisens Labdiscs. Seven of the scenarios used distance sensor, 4 used voltage sensor, 3 used temperature sensor, 2 used microphone sensor and 1 used light sensor. Again, the ideas were mostly in inquiry-based learning paradigm. Only one of the teaching scenario idea was in CS paradigm and the idea was similar to the one developed during the third training. The scenario included school community into measuring heat loss through the windows of the school building.

\section{DISCUSSION AND CONCLUSIONS}

The current study aimed to investigate how to improve teacher training so that teacher will adopt CS paradigm more effectively. The first research question was "How teachers adopt the CS related technical skills and value CS related teaching outcomes during the trainings?". The results show that it was difficult for the teachers to use the new technology: Globisens Labdiscs, Globilab software, Anecdata and Google Drive. After few training event, the teachers thought that they were more able to use the new technology and they had developed their technical skills. However, teachers' opinions about their skills of using Globilab software increased only slightly. According to diffusion of innovation theory (Roger, 1995) the innovation should not be too difficult to use. As it might get easier to use the Globilab software if teacher will get more experience, the next trainings should focus more on using the software for analysing the collected data. Also, in the data gathering phase teachers did not prefer using Anecdata platform and Google Drive. This suggests that some other platforms for data gathering could be considered for the next trainings.

The teachers' answers showed that they thought that CS has many potential benefits for students. Still, the teachers valued more highly the teaching outcome that were in inquiry-based learning paradigm (e.g., improvement of students' inquiry skills) than the outcomes in CS paradigm (e.g., students will help scientists with their work). Inquiry-based learning paradigm was already adopted by most of the teachers before the trainings because it is emphasised in Estonian National curriculum (National Curriculum for Basic School, 2014) and students' inquiry skills are evaluated in the national test (Pedaste, et al., 2017). The results indicate that the teachers did not adopt the new CS paradigm fully and the training could be improved. The trainings put emphasis on technical skills because teachers had to use the new technology and it was easier to try the new technology in a familiar paradigm (inquiry-based). Now, the teachers have the skills of using the Globisens Labdiscs and the focus of the following trainings could be more on CS paradigm. The CS tasks that teachers completed during the trainings were examples of CS projects but not ongoing real-life projects. As there are not many ongoing CS projects in Estonia where Globisens Labdiscs can be used, the next trainings could focus more on initiating new CS projects. This means that the problems in the community and city environment should be discussed with teachers, local citizens and scientists to initiate real-life CS projects that have a potential of guiding teachers towards using CS paradigm in their teaching.

The second research question was "How previously adopted inquiry-based learning paradigm affects teaches to adopt the CS paradigm?". In general, the teachers evaluated highly that they were able to complete the inquiry related steps of the tasks. Most of the teachers had adopted inquiry-based learning paradigm and had used inquiry-based learning approach in their classes before the training, but the number of teachers who had used sensors in their class was much lower. This suggests that teachers often use inquiry-based approach without using sensors. It could be that sensors were not available for the teachers, they did not know how to use the sensors in their classes or they did not feel the need to use

sensors as sensors are mostly used for inquiry-based learning in science and math classes (Buchanan, et al., 2016) but the teachers who participated in the study were teaching a variety of different subject 
(including languages, physical education etc.). Still, several teachers tried using Globisens sensors after training events which suggests that these teachers got enough knowledge, skills and confidence from the trainings to use the new technology in practice.

The previously adopted paradigm could have both positive and negative effect on adopting the CS paradigm. On one hand, the trainings showed that teachers who had used inquiry-based learning before had more skills that are needed in CS, but on the other hand, it was easier for the teachers to use the new technology in a paradigm that was already adopted by them rather than in the CS paradigm which was new.

The third research question was "How teachers implement CS paradigm while creating teaching scenarios?". The results again indicate that the teachers did not adopt the CS paradigm fully. The teachers created teaching scenarios that were mostly in inquiry-based learning paradigm. Implementing the CS paradigm into teaching scenarios is one step further from the adoption of the innovation (Damanpour \& Schneider, 2006). So, the future trainings should focus more on developing teaching scenario ideas in CS paradigm.

To sum up, the study shows that CS approach has potential benefits to be used in school and teachers see these benefits. The teachers had inquiry skills and they developed their technical skills that are needed for CS, but they did not adopt the CS paradigm fully. Adopting the new paradigm may take time and participating more in real-life CS project could help guiding teacher to actually implement the CS approach in school.

\section{ACKNOWLEDGEMENT}

Project „TU TEE - Tallinn University as a promoter of intelligent lifestyle (nr 2014-2020.4.01.160033) under activity A5 in the Tallinn University Centre of Excellence in Educational Innovation.

\section{REFERENCES}

Bonney, R. (1996). Citizen science: A lab tradition. Living Bird, 15(4), 7-15.

Bonney, R., Ballard, H. L., Jordan, R., McCallie, E., Phillips, T., Shirk, J., \& Wilderman, C. C. (2009). Public Participation in Scientific Research: Defining the Field and Assessing Its Potential for Informal Science Education. A CAISE Inquiry Group Report. Washington, D.C.: Center for Advancement of Informal Science Education (CAISE).

Bonney, R., Phillips, T. B., Ballard, H. L., \& Enck, J. W. (2016). Can citizen science enhance public understanding of science? Public Understanding of Science, 25(1), 2-16.

Branchini, S., Meschini, M., Covi, C., Piccinetti, C., Zaccanti, F., \& Goffredo, S. (2015). Participating in a citizen science monitoring program: implications for environmental education. PloS One, 10(7), $1-14$.

Buchanan, S., Harlan, M. A., Bruce, C. S., \& Edwards, S. L. (2016). Inquiry based learning models, information literacy, and student engagement: A literature review. School Libraries Worldwide, 22(2), 23-39.

Caruso, J. P., Israel, N., Rowland, K., Lovelace, M. J., \& Saunders, M. J. (2016). Citizen science: The small world initiative improved lecture grades and California critical thinking skills test scores of nonscience major students at Florida Atlantic University. Journal of Microbiology \& Biology Education, 17(1), 156-162.

Chase, S. K., \& Levine, A. (2018). Citizen science: exploring the potential of natural resource monitoring programs to influence environmental attitudes and behaviors. Conservation Letters, 11(2), 1-10.

Damanpour, F., \& Schneider, M. (2006). Phases of the adoption of innovation in organizations: effects of environment, organization and top managers. British Journal of Management, 17(3), 215-236.

Eastman, L., Hidalgo-Ruz, V., Macaya-Caquilpán, V., Nuñez, P., \& Thiel, M. (2014). The potential for young citizen scientist projects: a case study of Chilean schoolchildren collecting data on marine litter. Journal of Integrated Coastal Zone Management, 14(4), 569-579.

110 Journal of Strategic Innovation and Sustainability Vol. 15(3) 2020 
European Commission. (2018). OSPP-REC Open Science Policy Platform Recommendations. Retrieved from

https://ec.europa.eu/research/openscience/pdf/integrated_advice_opspp_recommendations.pdf\#vi ew $=$ fit\&pagemode $=$ none.

Fjukstad, B., Angelvik, N., Hauglann, M. W., Knutsen, J. S., Grønnesby, M., Gunhildrud, H., \& Bongo, L. A. (2018). Low-Cost programmable air quality sensor kits in science education. In Proceedings of the 49th ACM Technical Symposium on Computer Science Education (pp. 227232). ACM.

Flagg, B. (2016). Contribution of multimedia to girls' experience of citizen science. Citizen Science: Theory and Practice, 1(2)

Friesike, S., \& Schildhauer, T. (2015). Open Science: many good resolutions, very few incentives, yet. Incentives and Performance (pp. 277-289). Springer, Cham.

Haklay, M. (2013). Citizen science and Volunteered Geographic Information: Overview and Typology of Participation. In D. Sui, S. Elwood, \& M. Goodchild (Eds.), Crowdsourcing Geographic Knowledge (pp. 105-122). Dordrecht: Springer Netherlands.

Hiller, S. E. (2012). The impact of a citizen science program on student achievement and motivation: A social cognitive career perspective. Doctoral dissertation.

Hiller, S. E., \& Kitsantas, A. (2014). The effect of a horseshoe crab citizen science program on middle school student science performance and STEM career motivation. School Science and Mathematics, 114(6), 302-311.

Irwin, A. (1995). Citizen Science: A Study of People, Expertise and Sustainable Development. London: Routledge.

Kermish-Allen, R., Peterman, K., \& Bevc, C. (2018). The utility of citizen science projects in K-5 schools: measures of community engagement and student impacts. Cultural Studies of Science Education, 14(3), 627-641.

National curriculum for basic schools. (2014). Retrieved from https://www.riigiteataja.ee/akt/ 129082014020

Newman, G., Crall, A., Laituri, M., Graham, J., Stohlgren, T., Moore, J. C., . . \& Holfelder, K. A. (2010). Teaching citizen science skills online: Implications for invasive species training programs. Applied Environmental Education and Communication, 9(4), 276-286.

Neyland, E. (2011). Integrating online learning in NSW secondary schools: Three schools' perspectives on ICT adoption. Australasian Journal of Educational Technology, 27(1), 152-173.

Pedaste, M., Brikker, M., Rannikmäe, M., Soobard, R., Mäeots, M., \& Reiska, P. (2017).

Loodusvaldkonna õpitulemiuste hindamine. Retrieved from

http://haridusinfo.innove.ee/UserFiles/Organisatsioonist/ESF\%20tegevused/Loodusvaldkonna\%2 0e-hindamine.pdf.

Pedaste, M., Mäeots, M., Siiman, L. A., De Jong, T., Van Riesen, S. A., Kamp, E. T., . . \& Tsourlidaki, E. (2015). Phases of inquiry-based learning: Definitions and the inquiry cycle. Educational Research Review, 14, 47-61.

Rogers, E. (1995). Diffusion of innovation (4th ed.). The Free Press, New York.

Sharples, M., Aristeidou, M., Villasclaras-Fernández, E., Herodotou, C., \& Scanlon, E. (2017). The Sense-it App: A Smartphone Sensor Toolkit for Citizen Inquiry Learning. International Journal of Mobile and Blended Learning, 9(2), 16-38.

Silvertown, J. (2009). A new dawn for citizen science. Trends in Ecology \& Evolution, 24(9), 467-471.

Strasser, B., Baudry, J., Mahr, D., Sanchez, G., \& Tancoigne, E. (2019). Citizen Science? Rethinking Science and Public Participation. Science \& Technology Studies, 32, 52-76.

Wiggins A., \& Crowston, K. (2011). From Conservation to Crowdsourcing: A Typology of Citizen science. In Proceedings of the 2011 44th Hawaii International Conference on System Sciences (pp. 1-10). Washington, DC: IEEE Computer Society. 